\title{
COMPOSITION OF EXTRACTS ISOLATED FROM BLACK ALDER BARK BY MICROWAVE ASSISTED WATER EXTRACTION
}

\author{
* Alexandr Arshanitsa, Jevgenija Ponomarenko, Maris Lauberts, Vilgelmina Jurkjane, Lilija Jashina, \\ Alexandr Semenischev, Jegor Akishin, Galyna Telysheva \\ Latvian State Institute of Wood Chemistry, Latvia \\ *Corresponding author's email: arshanica@edi.lv
}

\begin{abstract}
The composition of extracts isolated from black alder bark by 'green' microwave assisted water extraction in the temperature range of $70-150^{\circ} \mathrm{C}$ was studied using the wet chemistry Folin-Ciocalteu method and Py-GC-MS/FID. The composition data were compared with those of the extracts obtained at the same temperature by accelerated solvent extraction (ASE) of bark. It was shown that microwave assisted extraction, compared with ASE, resulted in more significant transition of major cell wall components, including hemicelluloses and phenolics of lignin origination, into the solution. Depending on the microwave assisted extraction regimes, products with different portion of major cell wall components and secondary phenolic metabolites can be isolated that enlarge the possibilities of products valorisation. Thus, a significant promotion of secondary phenolic metabolites' transition into extracts as a result of microwave extraction was observed at $70{ }^{\circ} \mathrm{C}$. At that time the relative portion of carbohydrates in extracts was increased at high temperature extraction, combining dynamic and isothermal microwave heating. Water extraction of black alder bark in a microwave extractor revealed 25-50\% lower specific energy consumption and 1.8-2.6 times higher productivity in comparison with the conventional extraction, that is beneficial in view of the upscale and practical application of this innovative biomass processing.
\end{abstract}

Key words: Bark, extraction, microwave, plant phenols, carbohydrate.

\section{Introduction}

By the ecological factors, decreasing the $\mathrm{CO}_{2}$ emission is the global task that has to be solved by human society in the nearest future. Therefore, different branches of manufacturing within rural and industrial sectors of economy are challenged to find new technologies in order to reduce energy consumption and maximize the valorisation of the renewable raw material for the development of economic sustainability.

The biorefinery concept, which is defined as a range of combined technologies aimed at the waste free transformation of biomass into commodity or specialty chemicals and added value materials, is the fundamental approach for developing new and more sustainable processes (Morais \& Bogel-Lukasik, 2013; Rombaut et al., 2014). Wood biomass, renewable in the photosynthetic process, is an ideal feedstock for a wide range of processing since it does not affect food supplies (Tabasso et al., 2015; Popa \& Volf, 2018).

In each step of forest biomass conversion, a significant amount of waste is generated. The biggest underexploited lignocellulosic waste is tree bark, the output of which only in Latvia achieves $1 \mathrm{mln}$. $\mathrm{m}^{3}$ per year (LR Zemkopības Ministrija, 2018). Currently, bark is used mainly for heat production by direct combustion, which does not correspond to its potential. However, due to the presence of secondary metabolites with unique composition, bark can be used for valuable phytochemicals' isolation, although with a small output, but characterized with a high added value.

Alder (Alnus incana and Alnus glutinosa) is assessed as a biorefinery feed as it is the only native fast growing large tree with nitrogen fixating and deep phosphorus retrieval symbiosis characteristics in the Northern European region including the Baltic countries and because it has already been proposed for replenishment management of depleted soils in these areas (Thomsen, Ahrenfeld, \& Thomsen, 2013) In this context, alder barks have a high potential to be an integral part of biorefinery processes, as they contain valuable monomeric, oligomeric and polymeric compounds, which can be converted into numerous value-added products (Ren et al., 2017).

Based on the above-mentioned, in present work, liquid-solid extraction of black alder bark was studied as a subcomponent of bark biorefinery. Taking into account the main requirements of green chemistry, additives free deionized water was used as a solvent and microwave (MW) assisted heating was used as an alternative of conventional heating methods. The selection of the MW technology for the given study is associated with the fact that MW extraction in many cases was revealed as a more effective method in comparison with not only conventional methods, but also with modern advanced extraction methods, because extraction occurs as a result of changes in the cell structure caused by the electromagnetic irradiation and synergistic combination of two transport phenomena: heat and mass gradients working in the same direction as well (Veggi, Martinez, \& Meiriles, 2012).

The aim of the present work was evaluation of the effectiveness of black alder bark water MWassisted extraction, including that in terms of specific energy consumption and development of the optimal extraction regimes. The data obtained were compared with the results of extraction by the 
modern advanced accelerated solid ASE method where convective/conductive heat transfer takes place. For the realization of controlling the MW assisted extraction, a laboratory device of original construction was used. The effect of the extraction temperature and isothermal heating duration on the yield and composition of extracts removed was in focus of the present research. With this aim, Py-GCMS/FID and wet chemistry procedures, including the measurement of the total polyphenolic content, were used as the main analytical tools.

\section{Materials and Methods}

Bark removed by handle debarking of a 27 years' age black alder (Alnus glutinosa) tree harvested in Talsu municipality of Latvia was used as an object of investigation. The isolated bark was air dried $\left(\sim 20{ }^{\circ} \mathrm{C}\right)$ up to the water content of $9 \%$, then ground by a Retch 100 knife type mill equipped with a $2.00 \mathrm{~mm}$ sieve.

The MW extraction column of original construction consisted of a circular coaxial wave guide with three magnetrons (output MW power - $0.850 \mathrm{~kW}$ per each), an extraction chamber $\left(\mathrm{V}=1350 \mathrm{~cm}^{3}\right)$, power supply units, a vacuum pump, a cooling section, and a pressure relief valve was used for biomass extraction (Figure 1).

In each experiment, $108.50 \mathrm{~g}$ of bark (water content $=9.0 \%$ ) and $550.00 \mathrm{~g}$ of deionized water $\left(\mathrm{T}=18-20{ }^{\circ} \mathrm{C}\right)$ were loaded into the extraction chamber. After that the column was assembled and vacuum treatment of the suspension at the residual

a

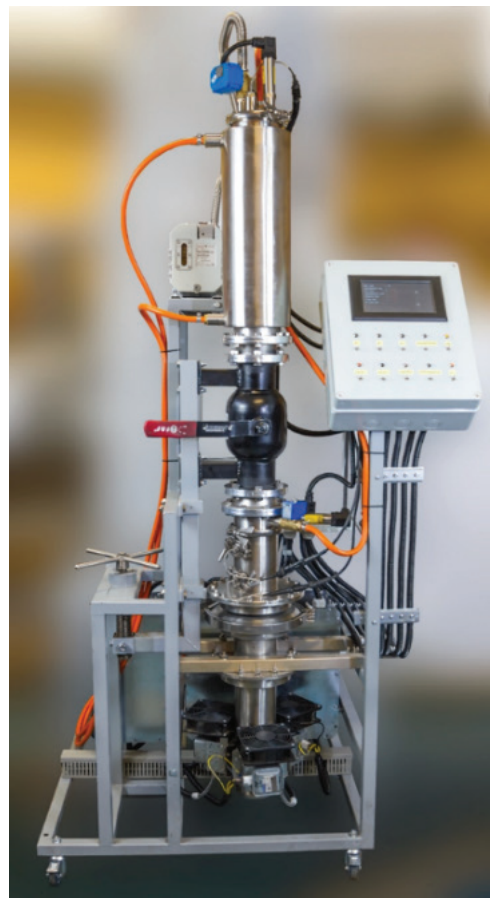

pressure of 50 mbar was done during $5 \mathrm{~min}$ to ensure the penetration of the solvent inside the substrate. Then, the atmospheric pressure in the chamber was recovered and continual microwave heating of the composition up to the desirable temperature varied in the range of $70-150{ }^{\circ} \mathrm{C}$ was performed, followed by the automatically controlled isothermal heating during 5-30 $\mathrm{min}$ that was achieved by the on/off action regime of microwave generators. After the exposition of the composition at a given temperature, the pressure inside the closed extraction chamber was removed by turning-on of the relief valve connected to the extraction chamber and the cooling section. After the 5-min exposition, the chamber was removed from the extraction column to be mounted into the screw gearing press to separate solid and liquid fractions. For each chosen temperature magnitude, one experiment was performed without the isothermal heating stage, e.g. a drop in pressure was done immediately after the achievement of the desirable temperature inside the extraction chamber. The liquid fraction enriched with extractives was filtered using Buchner funnel, followed by lyophilic drying. The yield of dry extracts in relation to dry bark was measured by weighing. The powder-like extracts were placed in a plastic box for freezing storage at $-17{ }^{\circ} \mathrm{C}$. The specific energy consumption, depending on the temperature value and extraction duration, was measured using a power indicator SENECA S604E-6-MOD. Each experiment was repeated three times and the data were averaged. The variation coefficient of measurement was $\leq 10 \%$. b

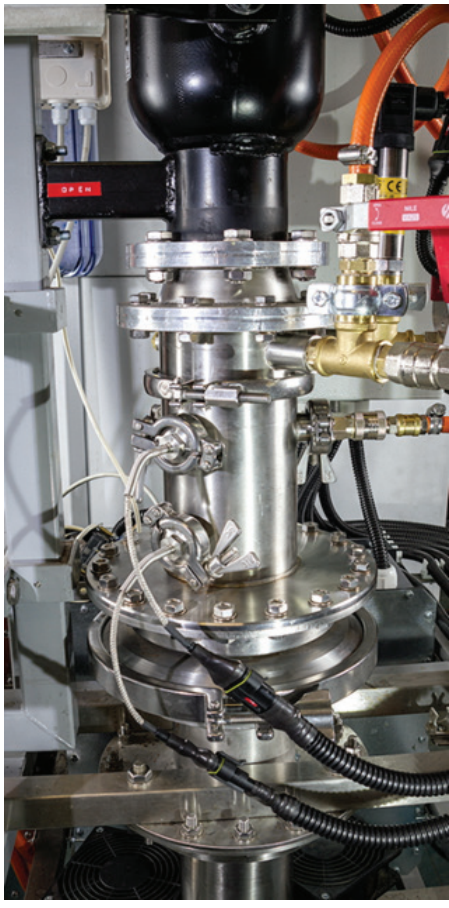

Figure 1. The column for MW assisted water extraction of black alder bark: common assembly view (a), view of extraction chamber (b). 
The ASE water extraction of bark was performed using a laboratory scale device DIONEX ASE. About $40.00 \mathrm{~g}$ of black alder bark was loaded into the extraction cell, followed by processing consisting of four repeated extraction cycles with a fresh portion of the solvent at temperatures varied in the range of $70-150{ }^{\circ} \mathrm{C}$ during 5 min per each cycle. Earlier, this regime was recognized as the optimal one in terms of the extract yield (Lauberts, 2018). For each experiment, $300 \pm 20 \mathrm{~mL}$ of the extractives' rich solvent were obtained. The yield of the lyophilic dried extract was measured by weighing. Each experiment was repeated three times and the data were averaged. Variation coefficient of measurement was $\leq 10 \%$.

The total phenolic content (TPC) of extracts was determined by wet chemistry methods using FolinCiocalteu reagent. The optical intensity of the resulted coloured complex at $765 \mathrm{~nm}$ was measured against gallic acid solution as a blank (Singleton, Orthofer, \& Lamuela-Raventos, 1999). The total phenolic contents were expressed as grams $(\mathrm{g})$ of gallic equivalents (GAE) per gram of a dried sample of the extract.

Py-GC/MS/FID analysis was performed using a Frontier Lab (Fukushima, Japan) Micro Doubleshot Pyrolyzer Py-3030D (pyrolysis temperature 500 ${ }^{\circ} \mathrm{C}$, heating rate $600{ }^{\circ} \mathrm{C} \mathrm{s}^{-1}$ ) directly coupled with the Shimadzu GC/MS/FID-QP ULTRA 2010 apparatus (Japan) equipped with a capillary column RTX-1701 (Restec, Metairie, Louisiana, USA) and a $60 \mathrm{~m} \times$ $0.25 \mathrm{~mm} \times 0.25 \mathrm{~mm}$ film (injector temperature of $250{ }^{\circ} \mathrm{C}$, ion source with $\mathrm{EI}$ of $70 \mathrm{eV}$, MS scan range $\mathrm{m} / \mathrm{z}$ of $15-350$, carrier gas helium at the flow rate of $1 \mathrm{~mL} \mathrm{~min}^{-1}$ and a split ratio of 1:30). The mass of the sample probe (residual moisture content $<1 \%$ ) was $1.00-2.00 \mathrm{mg}$. The oven program was as follows: $1 \mathrm{~min}$ isothermal at $60{ }^{\circ} \mathrm{C}$, followed by $6{ }^{\circ} \mathrm{C} \mathrm{min}-1$ to $270{ }^{\circ} \mathrm{C}$, and the final hold at $270{ }^{\circ} \mathrm{C}$ for $10 \mathrm{~min}$. The mass spectrometer was operated in electron impact mode using $70 \mathrm{eV}$ electron energy. The identification of the individual compounds was performed based on GC/MS chromatography using Library MS NIST 11 and NIST $11 \mathrm{~s}$, whereas the relative area of the peak of individual compounds was calculated using Shimadzu software based on GC/FID data. The summed molar areas of the relevant peaks were normalized to $100 \%$, and the data for four repetitive pyrolysis experiments were averaged. $\mathrm{CV}$ of measurements was $\leq 8 \%$.

\section{Results and Discussion}

Bark refers to lignocellulosic biomass, which is mainly composed of carbohydrate polymers: cellulose, hemicellulose and aromatic polymer lignin. It also contains extractives and ash. The chemical composition of bark differs depending on the tree species. Bark differs chemically from stem wood with an overall higher proportion of ash and extractives
(Marmol et al., 2019; Leite \& Pereira, 2017; Neiva et al., 2018). Extractives are composed of a wide array of individual hydrophobic and hydrophilic compounds ranging from terpenoids and steroids, fats, and waxes to phenolic compounds including stilbenes, tannins and flavonoids. The most characteristic feature of the Alnus genus is the occurrence of large quantities of diarylheptanoids and their glycosides in different morphological parts of the tree. It is known, that many of valuable phenolic compounds are present not only within cytosolic spaces but are also bound within plant cellular walls. Plant cell walls consist of a series of complex structural polysaccharides such as cellulose, hemicellulose and lignin (an aromatic polymer) and even proteins. This structure is what confers to the cells stability and resistance to the extraction of the intracellular components (Gligor et al., 2019). Therefore, one of the objectives of this study was to evaluate the influence of the MWassisted water extraction in different conditions not only on secondary metabolites' isolation but also on the transition of the cell wall main components into solution. The advanced ASE extraction method was used as the reference. The yield of the water extracts obtained from black alder bark by ASE extraction varied from $19.2 \%$ (on DM) at $70{ }^{\circ} \mathrm{C}$ up to $28.9 \%$ at $150{ }^{\circ} \mathrm{C}$. The yield of the water extracts obtained by MW-assisted extraction increased with increasing temperature and varied from $15.4 \%$ (on DM) to $26.4 \%$ depending on the extraction conditions. In this case, the effect of the temperature magnitude on the yield of extractives was more pronounced in comparison with that of the extraction duration.

The composition of black alder bark extracts was studied, using the Py-GC-MS/FID method well known as analytical pyrolysis. This method is widely used for the characterization of the chemical composition of lignocellulosic biomass by the determination of pyrolysis products referring to the definite biomass components (González-Vila, 1997). The application of AP for the studies of the composition of the obtained extracts allowed simultaneous evaluation of the transition to the extracts of all components of bark biomass, including high molecular weight cell wall components (carbohydrates and lignin) and their derivatives, lipophilic and hydrophilic extractives. The products of carbohydrates' thermal degradation in conditions of AP consist of aliphatic acids and esters, aliphatic alcohols, aliphatic aldehydes and ketones, furan and pyran derivatives, cyclopentane derivatives and sugars. The lignin degradation products consist of methoxylated phenols, guaiacyl (G-) and syringyl (S-) derivatives (Figure 2).

The method is mostly used for the characterization of the main biomass components in situ; however, there are some studies concerning the application of 


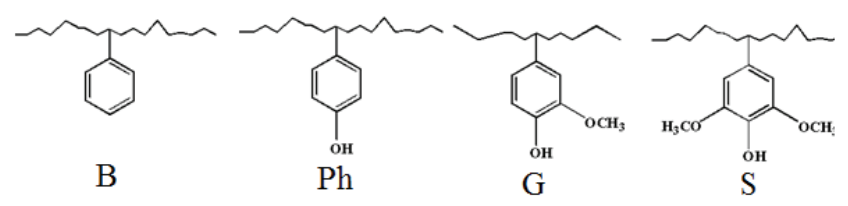

Figure 2. Classification of the aromatic pyrolysis products.

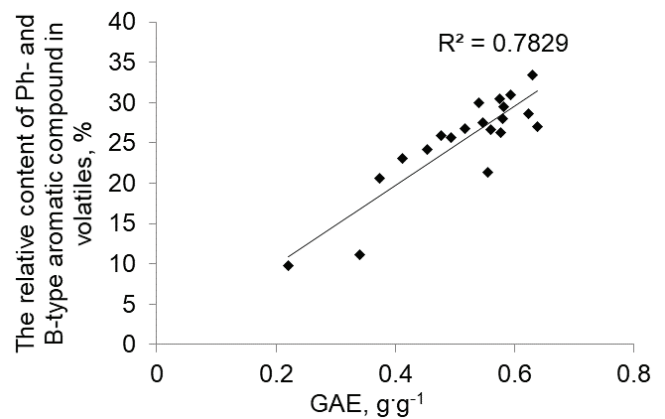

Figure 3. Correlation between the total phenols $\left(\mathrm{GAE} g \cdot \mathrm{g}^{-1}\right)$ content in extracts isolated from black alder bark by both extraction methods and relative content of non-methoxylated phenols in volatiles, determined by Py-GC-MS/FID.

Py-GC-MS/FID for the characterization of extractives isolated from plant substrates (Ohra-aho, 2017). As the lignocellulosic material under study contains lignin, which consists only of G- and S-units, the normalized area of peaks in Py-GC-MS/FID chromatograms for products, related to $\mathrm{B}$ - and $\mathrm{Ph}$-type phenols, reflects the content of phenolic extractives in the samples of isolated extracts.

This assumption is confirmed by the strong positive correlation between the content of total phenols, determined as GAE $\mathrm{g}^{\cdot} \mathrm{g}^{-1}$ of the extract and the relative content of non-methoxylated aromatic volatiles in pyrolysis products (Figure 3 ).

Other significant groups of compounds detected in the AP volatiles are degradation products of lipophilic and $\mathrm{N}$-containing compounds present in extractives.

To get information about the extracts' and parent biomass' compositions, areas of pyrolytic chromatograms peaks, typical for carbohydrates, lignin, lipophilic and hydrophilic extractives degradation products and N-containing products, were summed up and normalized to $100 \%$. According to the obtained data, the volatiles of the parent black alder bark consist of $72.6 \%$ of carbohydrates derived compounds; $20.1 \%$ of lignin derived compounds (Gand S-type phenols); 5.5\% of hydrophilic extractives derived compounds ( $\mathrm{Ph}$ - and B-type phenols); 1.6\% of lipophilic extractives derived compound and $0.2 \%$ of N-containing compounds. Carbohydrates are also the main constituents of all the obtained water extracts (Figure 4). The carbohydrate content tends to increase with increasing ASE temperature. The composition of extracts, obtained by MW-assisted extraction without isothermal heating at the corresponding temperature, is close to that of water extracts, obtained by ASE extraction (isothermal heating time $=20 \mathrm{~min}$ ). However, the MW assisted extraction revealed the specific energy consumption lower by $25-52 \%$ and a higher productivity of the process, which was defined as the average yield of extracts on the DM of bark per time unit of processing.

The productivity of MW assisted extraction varied in the range of $1.3-1.1 \% \mathrm{~min}^{-1}$ vs $0.6-0.5 \% \mathrm{~min}^{-1}$ for ASE processing. The relative content of carbohydrates derived products in volatiles of MW extracts was slightly dependent on the temperature magnitude when only short term dynamic MW heating took place and was about $60 \%$. A similar dependence was observed for ASE processing although the long term (20 min) heating was performed in this case (Figure 4). The ratio of carbohydrates derived products to lignin derived products is $4.4-5.8$ for extracts, obtained by ASE extraction and 5.2-5.7 for extracts, obtained by $\mathrm{MW}$-assisted extraction. This ratio for parent black alder bark is 3.6. The composition of extracts, obtained by MW-assisted extraction including 15 and $30 \mathrm{~min}$ of isothermal heating at the corresponding temperature $\left(70-110^{\circ} \mathrm{C}\right)$, is close to that of the abovedescribed extracts; however, it differs at $130{ }^{\circ} \mathrm{C}$ and strongly differs at $150{ }^{\circ} \mathrm{C}$ extraction temperatures. In contrast to the extracts obtained by ASE extraction, the extracts obtained by MW-assisted extraction have a significantly higher content of carbohydrates derived volatiles (it reaches $78 \%$ at $150{ }^{\circ} \mathrm{C}$ ). This indicates the promoting effect of MW irradiation on the plant cell degradation. It was proven by the fact that the 


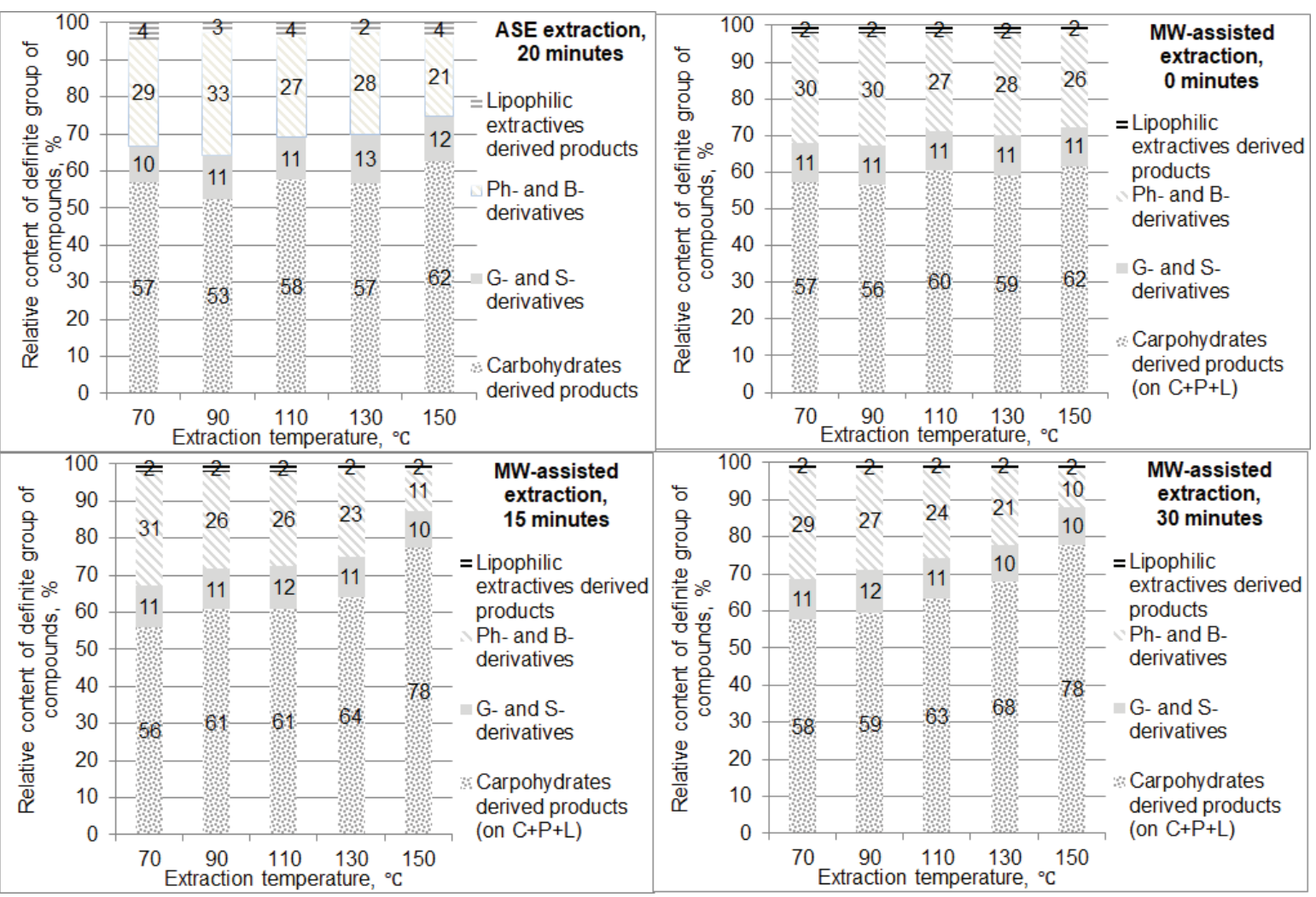

Figure 4. Composition of black alder bark water extracts, depending on extraction methods and process conditions.

extracts obtained by MW-assisted extraction have a higher portion of lignin derived methylated phenols in aromatic volatiles in comparison to the extracts obtained by ASE extraction. There is a strong positive correlation between the carbohydrates derived products' content and the lignin-derived products' content, pointing to cell wall degradation (Figure 5).

As extracts, obtained by MW-assisted extraction, have a higher relative content of pyrolysis products related to cell wall components, it can be concluded that the MW-assisted extraction much more affects the degradation of the cell wall in comparison to the ASE extraction. The especially strong degradation of the wall cell was observed for extracts, obtained by the MW-assisted extraction at $150{ }^{\circ} \mathrm{C}$ at $15 \mathrm{~min}$ and 30 min of extraction (Figure 5).

Phenolic extractives are important components of the obtained water extracts (Figure 4). However, it is

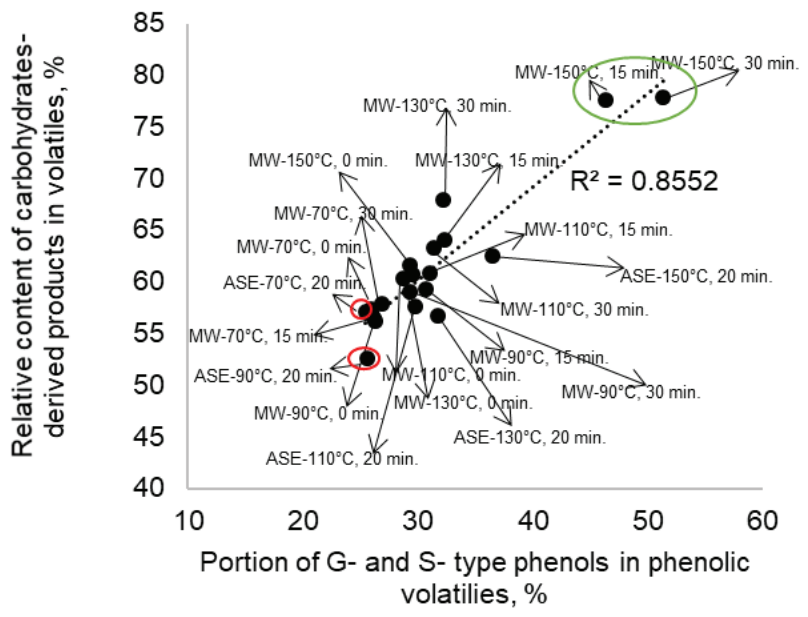

Figure 5. Correlation between the portion of lignin-derived products in aromatic volatiles and relative content of carbohydrates derived products in total pyrolysis volatiles. 


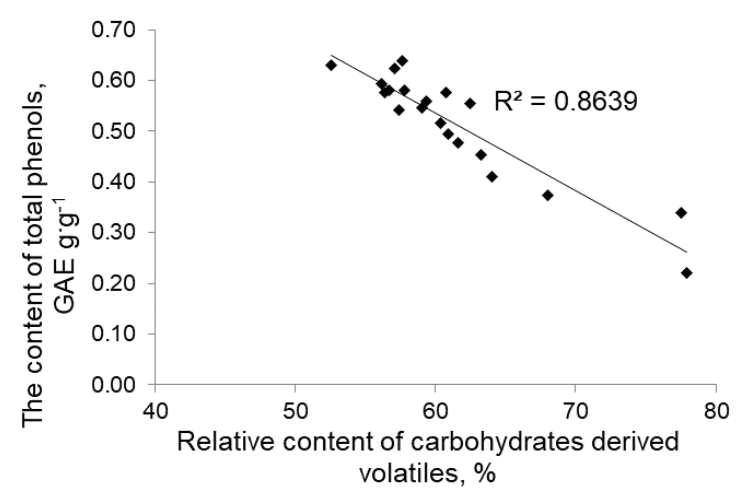

Figure 6. Correlation between the relative content of carbohydrates derived products in volatiles of extracts isolated by both extraction methods and content of total phenols $\left(\mathrm{GAE} \mathrm{g}^{\cdot} \mathrm{g}^{-1}\right)$ in them.

\section{Transition of the phenolic compounds (hydrophilic extractives) to extracts,} depending on extraction conditions

\begin{tabular}{|l|c|c|}
\hline \multicolumn{1}{|c|}{ Extraction regime } & Total phenols, GAE g $\cdot \mathrm{g}^{-1}$ & $\begin{array}{c}\text { The ratio of hydrophilic (phenolic) extractives derived py- } \\
\text { rolysis products to lipophilic extractives derived products }\end{array}$ \\
\hline ASE-70 ${ }^{\circ} \mathrm{C}, 20 \mathrm{~min}$ & 0.62 & 6.4 \\
\hline $\mathrm{MW}-70{ }^{\circ} \mathrm{C}, 0 \mathrm{~min}$ & 0.54 & 14.6 \\
\hline $\mathrm{MW}-70{ }^{\circ} \mathrm{C}, 15 \mathrm{~min}$ & 0.59 & 15.7 \\
\hline $\mathrm{MW}-70{ }^{\circ} \mathrm{C}, 30 \mathrm{~min}$ & 058 & 15.4 \\
\hline ASE-90 ${ }^{\circ} \mathrm{C}, 20 \mathrm{~min}$ & 0.63 & 13.1 \\
\hline $\mathrm{MW}-90^{\circ} \mathrm{C}, 0 \mathrm{~min}$ & 0.58 & 13.5 \\
\hline $\mathrm{MW}-90^{\circ} \mathrm{C}, 15 \mathrm{~min}$ & 0.58 & 13.2 \\
\hline $\mathrm{MW}-90^{\circ} \mathrm{C}, 30 \mathrm{~min}$ & 0.56 & 12.6 \\
\hline $\mathrm{ASE}-110^{\circ} \mathrm{C}, 20 \mathrm{~min}$ & 0.64 & 7.0 \\
\hline $\mathrm{MW}-110^{\circ} \mathrm{C}, 0 \mathrm{~min}$ & 0.52 & 12.9 \\
\hline $\mathrm{MW}-110^{\circ} \mathrm{C}, 15 \mathrm{~min}$ & 0.49 & 13.1 \\
\hline $\mathrm{MW}-110^{\circ} \mathrm{C}, 30 \mathrm{~min}$ & 0.45 & 16.0 \\
\hline $\mathrm{ASE}-130^{\circ} \mathrm{C}, 20 \mathrm{~min}$ & 0.58 & 12.6 \\
\hline $\mathrm{MW}-130^{\circ} \mathrm{C}, 0 \mathrm{~min}$ & 0.55 & 13.8 \\
\hline $\mathrm{MW}-130^{\circ} \mathrm{C}, 15 \mathrm{~min}$ & 0.41 & 12.8 \\
\hline $\mathrm{MW}-130^{\circ} \mathrm{C}, 30 \mathrm{~min}$ & 0.37 & 12.7 \\
\hline ASE-150 ${ }^{\circ} \mathrm{C}, 20 \mathrm{~min}$ & 0.55 & 5.6 \\
\hline $\mathrm{MW}-150^{\circ} \mathrm{C}, 0 \mathrm{~min}$ & 0.48 & 14.7 \\
\hline $\mathrm{MW}-150^{\circ} \mathrm{C}, 15 \mathrm{~min}$ & 0.34 & 6.7 \\
\hline $\mathrm{MW}-150^{\circ} \mathrm{C}, 30 \mathrm{~min}$ & 0.22 & 4.6 \\
\hline $\mathrm{Black}$ alder bark & & 3.6 \\
\hline
\end{tabular}

impossible to evaluate the effect of the MW-assisted degradation of the cell wall on the transition of the phenolic compounds to the extracts, using the content of total phenols, GAE $\mathrm{g} \mathrm{g}^{-1}$, due to the dilution effect of carbohydrates (Figure 6).

The transition of the phenolic extractives to the extracts can be evaluated using the ratio of $(\mathrm{Ph}+\mathrm{B})$ aromatic volatiles to lipophilic extractives derived products (Table 1). This approach is based on the well-known data of the poor solubility of lipophilic extractives in water even at a high extraction temperature. As a result, this ratio for parent black alder bark enriched with a lipophilic compound is 3.6 and varies from 5.6 to 16.0 for the obtained water extracts. It can be noted that, at $70{ }^{\circ} \mathrm{C}$, the extracts obtained by microwave-assisted extraction have significantly 
higher ratios of phenolic extractives derived volatiles to lipophilic extractives derived volatiles. The above mentioned fact points to a higher transition of the phenolic extractive compound from the bark to the extracts under the MW-treatment (Table 1).

Exemplified by black alder bark, the results obtained indicate that microwave assisted extraction revealed itself as a flexible and low energy expensive method of tree bark processing that allows controlling the composition of the isolated extracts. It can be explained by the specific effect of MW irradiation, promoting the process of cell wall degradation and the high solubility of secondary metabolites in the presence of two attended factors: temperature and polar solvent. For complete clarification, this 'non-thermal effect' of microwave needs the further comprehensive research. The magnitude of the microwave power introduced into the substrate and the duration of microwave irradiation are tools, the variation of which allows controlling the transition of secondary metabolites and the main cell wall components to the extracts.

\section{Conclusions}

1. It has been shown that, at a given temperature, the effect of water microwave assisted extraction on the degradation of black alder bark cell wall is more pronounced in comparison to that achieved by ASE water extraction.
2. The combination of dynamic and isothermal heating regimes at the high temperature $\mathrm{MW}$ assisted extraction leads to a dramatic increase in the content of hemicellulose and phenolics of lignin origination in extracts.

3. In comparison with conventional ASE extraction, the MW treatment is more promoting the transition of secondary phenolic metabolites from the plant cell into extracts. The effect is most marketable at $70{ }^{\circ} \mathrm{C}$.

4. Depending on the MW extraction regimes, a different portion of secondary metabolites and major biomass components in extracts can be achieved. This enlarges the possibility of bark extracts valorisation.

5. Water extraction of black alder bark in a MW extractor revealed by $25-50 \%$ lower specific energy consumption and 1.8-2.6 times higher productivity in comparison with conventional ASE.

\section{Acknowledgements}

The project ERAF No. 1.1.1.1/18/A/182: 'Innovative green extraction process, using water, with elaboration of microwave hybrid reactor and mechano-chemical biomass pre-treatment, creating a new biorefinery cluster oriented to phytochemicals and biomaterials production from underexploited tree biomass' is gratefully acknowledged.

\section{References}

Popa, V., \& Volf, I. (2018). Biomass as Renewable Raw Material to Obtain Bioproducts of High-tech Value. Elsevier. DOI: 10.1016/C2015-0-05810-5.

Gligor, O., Mocan, A., Moldovan, C., Locatelli, M., Crian, G., \& Ferreira, I.C. (2019). Enzyme-assisted extractions of polyphenols - a comprehensive review, Trends in Food Science \&Technology, DOI: 10.1016/j.tifs.2019.03.029.

González-Vila, F.J., Gutiérrez, A., Martin, F., \& Verdejo, T. (1997). Application of analytical pyrolysis to the characterization of Eucalyptus extractives and pitch deposits from a pulp mill. Journal of Analytical and Applied Pyrolysis, 40-41, 501-510. DOI: 10.1016/S0165-2370(97)00018-1.

LR Zemkopības ministrija. (LR ministry of agriculture). (2018). Meža nozare skaiț̣os un faktos. (Latvian forest sector in facts and figures). Retrieved February 16, 2020, from https://www.zm.gov.lv/mezi/statiskaslapas/nozares-informacija/buklets-meza-nozare-skaitlos-un-faktos-?nid=1106\#jump. (in Latvian).

Lauberts, M. (2018). Isolation of polyphenols from different plant biomass processing residues applied environmentally friendly extraction methods and comprehensive characterization of the products obtained. Summary of Doctoral Thesis, Latvian University, Riga, p. 31.

Leite, C., \& Pereira, H. (2017). Cork-Containing Barks-A Review. Front. Mater. 3:63. DOI: 10.3389/ fmats.2016.00063.

Marmol, I., Quero, J., Jiménez-Moreno, N., Rodríguez-Yoldi, M.J., \& Ancín-Azpilicueta, C. (2019). A systematic review of the potential uses of pine bark in food industry and health care. Trends in Food Science \& Technology 88, 558-566. DOI: 10.1016/j.tifs.2018.07.007.

Morais, A., \& Bogel-Lukasik, R. (2013). Green chemistry and the biorefinery concept. Sust. Chem. Proc 1:18. DOI: $10.1186 / 2043-7129-1-18$.

Neiva, D.M., Araújo, S., Gominho, J., de Cássia Carneiro, A., \& Pereira, H. (2018). Potential of Eucalyptus globulus industrial bark as a biorefinery feedstock: Chemical and fuel characterization. Industrial Crops \& Products 123, 262-270. DOI: 10.1016/j.indcrop.2018.06.070.

Ohra-aho, T. (2017). Characterization of lignocellulose components by analytical pyrolysis gas chromatography mass spectrometry: Dissertation. Espoo: Aalto University 
Ren, X., He, T., Chang, Y., Zhao Y., Chen, X., Bai, S., Wang, L., Shen, M., \& She, G. (2017). Review. The Genus Alnus, A Comprehensive Outline of Its Chemical Constituents and Biological Activities. Molecules. (22), 1383. DOI: 10.3390/molecules22081383.

Rombaut, N., Tixier, A., Bily, A., \& Chemat, F. (2014). Green extraction process of natural products as tools for biorefinery. Biofuels, Bioprod. 8 Bioref. 8 (4), DOI: 10.1002/bbb.1486.

Singleton, V.L., Orthofer, R., \& Lamuela-Raventos, R.M. (1999). Analysis of total phenols and other oxidation substrates and antioxidants by means of folin-ciocalteu reagent. Methods Enzymol. 299, 152-178. DOI: 10.1016/S0076-6879(99)99017-1.

Tabasso, S., Carnraglio, D., Calcio Gaudino, E., \& Gravotto, G. (2015). Microwave, ultrasound, and ball mill procedures for bio-waste valorisation. Green Chem. 17, 684-693. DOI: 10.1039/C4GC01545B.

Thomsen, T.P., Ahrenfeld, J., \& Thomsen, S.T. (2013). Assessment of a novel alder biorefinery concept to meet demands of economic feasibility, energy production and long term environmental sustainability. Biomass and Bioenergy. (53), 81-94. DOI: 10.1016/j.biombioe.2013.02.022.

Veggi, P.C., Martinez, J., \& Meiriles, M.A. (2012). Fundamental of Microwave extraction. In: Chemat, F., Cravotto, G. (Ed.) Microwave assisted Extraction for Bioactive Compounds: Theory and Practice, Springer Science \& Business Media, 15-50. 